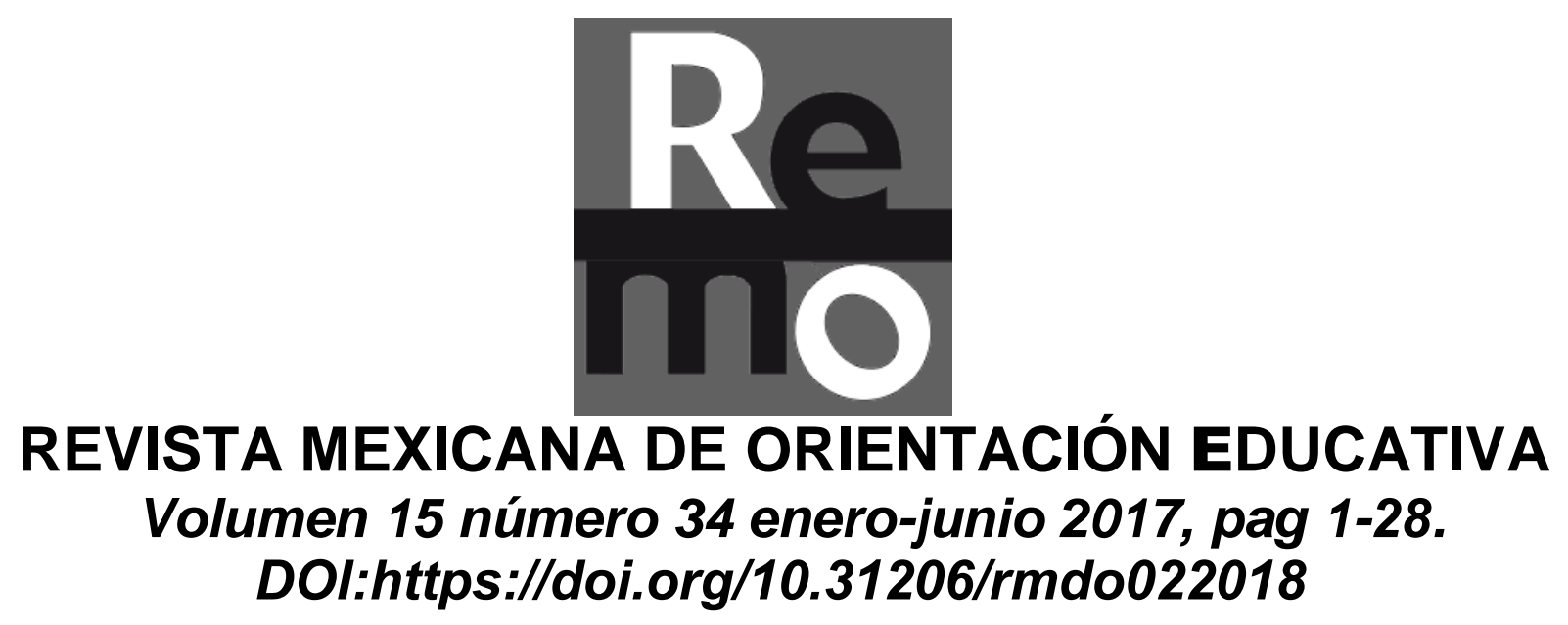

\title{
Síndrome del Dr. Jekyll y Mr. Hyde: Democracia, justicia social y pedagogía crítica en escuelas populares
}

Juan Luis Isunza Hernández ${ }^{1}$

\section{RESUMEN:}

Este artículo sintetiza algunos de los puntos fundamentales de una investigación concluida sobre escuelas populares en el Estado de México, en ella se analiza el surgimiento de una organización social que tutela más de 100 escuelas de distintos niveles. A través de un análisis hermenéutico crítico se interpretan tres categorías: democracia, justicia social y pedagogía crítica, que son la base discursiva sobre la que se sustenta el trabajo educativo que realiza la Unión Popular Revolucionaria Emiliano Zapata (UPREZ). Para ello se desarrolló un trabajo empírico, consistente en entrevistas con dirigentes, directivos, maestros y alumnos para contrastar los diferentes discursos. El surgimiento de las escuelas populares, el proyecto político que enarbolan y las alternativas educativas que generan ante la problemática que

\footnotetext{
${ }^{1}$ Licenciado en Periodismo y Comunicación Colectiva por la Universidad Nacional Autónoma de México (UNAM). Maestro en Investigación de la Educación por el Instituto Superior de Ciencias de la Educación del Estado de México (ISCEEM). Estudiante del Doctorado en Ciencias de la Educación (ISCEEM). Correo: juanluisisunza@hotmail.com.
} 
existe en la educación media superior en el Estado de México, son los asuntos fundamentales de este escrito.

PALABRAS CLAVE: Educación popular, democracia, justicia social y pedagogía crítica.

\section{ABSTRACT:}

This article summarizes some of the fundamental points of a completed research on popular schools at the state of Mexico, in which the emergence of a social organization in the entity that supervicer more than 100 schools of different levels is analyzed. Through a critical hermeneutical analysis, three categories are interpreted: democracy, social justice and critical pedagogy, which are the discursive base on which the educational work carried out by the Popular Revolutionary Union Emiliano Zapata (UPREZ) is based. For this, an empirical work was developed, consisting of interviews with leaders, managers, teachers and students to contrast speeches and practices. The emergence of popular schools, the political project that they raise up alternatives they generate in the face of the problems that exist in upper secondary education in satet of Mexico are the fundamental issues of this writing. KEY WORDS: Popular education, democracy, social justice and critical pedagogy.

\section{RESUMO:}

Este artigo resume alguns dos pontos-chave de uma pesquisa concluída em escolas populares no estado do México, que analisa o surgimento de uma organização social que protege mais de 100 escolas de diferentes níveis. Através de uma análise hermenêutica crítica, três categorias são interpretadas: democracia, justiça social e pedagogia crítica, que são a base discursiva em que o trabalho educacional realizado pela União Popular Revolucionária Emiliano Zapata (UPREZ) é baseado. Realizou-se um trabalho empírico, consistindo em entrevistas com líderes, gestores, professores e alunos para contrastarem os diferentes discursos. O surgimento das escolas populares, o projeto político que eles levantam e as alternativas educacionais que geram diante dos problemas que existem no ensino secundário superior no estado do México, são as questões fundamentais desta escrita. 
PALAVRAS-CHAVE: Educação popular, democracia, justiça social e pedagogia crítica.

Fecha de recepción: 21 de enero de 2018

Fecha de aprobación: 20 de abril de 2018

\section{INTRODUCCIÓN}

Este artículo está organizado en cuatro partes, en la primera se señalan algunas de las particularidades que presenta el sistema educativo en el Estado de México, con relación a las escuelas populares o escuelas de organización, como las llaman funcionarios educativos de la entidad, se hace una breve historia de las condiciones que dieron origen a este sector de escuelas, agrupadas en la Unión Popular Revolucionaria Emiliano Zapata (UPREZ). En un segundo momento, con datos del Instituto Nacional para la Evaluación de la Educación (INEE) en referencia a cobertura, financiamiento de las escuelas (públicas o privadas) y eficiencia terminal en educación media superior, se hacen una serie de consideraciones del discurso gubernamental que establece que:

Una buena educación constituye el mecanismo más importante para la inclusión social en el tránsito de una generación a la siguiente (Cepal, 2004). La educación permite a las personas mejorar sus condiciones de vida y posibilidades de movilidad social; por tanto, la ampliación de oportunidades educativas es una vía para promover la justicia y la equidad. (INEE, 2011, pág. 9) ${ }^{2}$

En la tercera parte del trabajo se señalan algunas consideraciones sobre justicia social, a la luz de los referentes teóricos que hablan de igualdad de posiciones e igualdad de oportunidades, de sus diferencias y de la importancia que tiene para las escuelas populares el discurso de la justicia. Por último, se analizan tres ideas que en educación media superior dan origen a discursos redentores: a mayor escolaridad mayores posibilidades de empleo, la escuela como espacio de formación del ciudadano y el lugar en donde se construyen procesos de inclusión

2 Página de internet consultada el día 1 de febrero de 2018 en: http://publicaciones.inee.edu.mx/buscadorPub/P1/D/235/P1D235.pdf. 
social, se forma el sujeto crítico, lo que tiene una relación directa con ideas de democracia y pedagogía crítica, formas de subjetivación de los individuos que en los marcos de la escuela interactúan: orientadores, maestros, directivos, alumnos y padres de familia.

\section{DESARROLLO}

\section{Haciendo un poco de historia no oficial}

La gran oleada de movimientos guerrilleros, de organizaciones sociales de izquierda ${ }^{3}$ y de luchas sindicales en contra del corporativismo, se dan después del movimiento estudiantil de 1968 (aunque anteriormente ya existían movimientos armados en México, es durante la década de los 70's y 80's que se multiplica el número de organizaciones guerrilleras, resultado de la brutal represión gubernamental). ${ }^{4}$ En el caso del Estado de México los activistas de izquierda, influenciados por la ideología marxista, apostaron a la organización popular como punta de lanza para la transformación radical de la sociedad, vía la lucha armada. Provenían principalmente de las universidades públicas, de las organizaciones sindicales y del ala más crítica de la iglesia católica que reivindica la Teología de la Liberación. $^{5}$

Los territorios a los que estos activistas de izquierda llegaron, se concentraban en el oriente del Estado de México, que desde los 50's fue el lugar al que llegaban los desplazados del entonces Distrito Federal, como consecuencia de la llamada modernización y encarecimiento de la vivienda en la hoy nombrada Ciudad de México. Municipios del Estado de México como Nezahualcóyotl, Los Reyes, Chimalhuacán, Chalco, Ixtapaluca, Ecatepec, entre los principales, recibieron no sólo a la población desplazada del Distrito Federal, sino también a personas de otros

\footnotetext{
${ }^{3}$ Para un conocimiento más profundo sobre organizaciones sociales de izquierda, sus orígenes, sus luchas y sus conquistas en los terrenos sociales y políticos, se puede consultar el libro de Silvia Bolos Organizaciones Sociales y Gobiernos Municipales, editado por la Universidad Iberoamericana en 2003, $335 \mathrm{pp}$.

${ }^{4}$ Sobre el tema, una buena referencia es el libro México Armado: 1943-1981, de Laura Castellanos, Editorial Era, de 2007, 383 pp.

${ }^{5}$ La obra de Franz Fanon y la teoría de la dependencia contribuyeron a generar otras corrientes de pensamiento crítico en América Latina. Dos de ellas, e interrelacionadas, son la Teología de la Liberación... y la Filosofía de la Liberación... La Teología de la Liberación se circunscribió, en sus comienzos, a América Latina... (Mignolo, 2001, pág. 2)
} 
estados de la República Mexicana, como resultado de un proceso de emigración interna de hombres y mujeres que buscaban en la capital del país mejores condiciones de vida. ${ }^{6}$

Estos activistas de izquierda, aplicaron la idea maoísta de Línea de Masas (influenciados por las ideas de la Revolución China de Mao Tse-Tung: oír al pueblo, ir al pueblo). Acumulando experiencias de organización comunitaria, para la empresa final: la transformación radical de la sociedad. Los ejes de organización comunitaria que se plantearon en un principio eran tres: reivindicación de subsidios alimentarios (tortibonos, tiendas CONASUPO y lecherías Liconsa), exigencia de servicios públicos (guarniciones, banquetas, drenaje, electricidad) e instalación de escuelas, hospitales y mercados, lo que era muy propicio dadas las condiciones sociales en las que surgieron estos municipios del oriente del Estado de México. Este último punto y particularmente la creación de escuelas fue un asunto de primer orden, como estrategia de lucha, pues se consideraba a la educación el espacio natural para dotar de conciencia social, de conciencia de clase, a la población que de manera cotidiana sufría los embates de los explotadores y en consecuencia, tenía ahí, guardada, una conciencia de transformación social en bruto, que necesitaba ser despertada por los hombres que representaban la vanguardia revolucionaria, que tenían una visión más clara y en consecuencia más consciente, de los caminos para la transformación de las condiciones materiales de vida centrada en la explotación del hombre por el hombre: los dirigentes de las organizaciones de izquierda. ${ }^{7}$

En este contexto nacen las escuelas populares o escuelas de organización, nombradas así por funcionarios del gobierno del Estado de México, agrupando en

\footnotetext{
${ }^{6}$ Aunque paradójicamente la gente que pobló los municipios del Estado de México, particularmente Nezahualcóyotl, se enfrentó al problema de especulación de la tierra lo que generó una inconformidad social muy grave, provocando la intervención del gobierno federal encabezado en aquel entonces por Luis Echeverría Álvarez. El cineasta Gustavo Alatriste Jr. lo reflejó en su filme QRR (Quien Resulte Responsable) un documental donde se exhibe el rostro oscuro del Nezahualcóyotl de aquellos años, ese que era sinónimo de especulación de la tierra, delincuencia y marginación.

${ }^{7}$ Las ideas de este párrafo son, por supuesto, motivo de debate y polémica. Lo que se intenta señalar aquí es el discurso que prevalecía en los dirigentes de izquierda de aquella época, influenciados por un marxismo dogmático. Coloco comillas en aquellas palabras que, de acuerdo a mi criterio, son motivo de debate y polémica, para señalar gráficamente su relatividad.
} 
este término a un variopinto número de organizaciones que tienen distinto origen, ideología, formas de organización, relación entre docentes, administración escolar y propuesta pedagógica. En esta generalidad se agrupa incluso a las escuelas de Antorcha Campesina, cuyos dirigentes gobiernan varios municipios del Estado de México bajo las siglas del Partido Revolucionario Institucional (PRI).

El punto en común de todos estos proyectos educativos es su origen autogestionario en donde se involucran procesos comunitarios de padres de familia, dirigentes sociales, autoridades comunales, alumnos. Escuelas que se inician a pesar de la oposición gubernamental, fuera de toda planeación y como parte de las estrategias de lucha para impulsar demandas en otros rubros. La disyuntiva en relación al objetivo de transformación social, a la que se enfrenta en su origen el proyecto político de la Unión Popular Revolucionaria Emiliano Zapata (UPREZ), está entre decidir una vía armada revolucionaria o una vía democrática electoral y de organización social. Dos acontecimientos nacionales ${ }^{8}$ que han dejado honda huella en los procesos reivindicatorios actuales precipitan el camino que esta organización va a tomar. El primero de ellos es el proceso electoral federal de 1988, donde el cuestionado resultado oficial, desata una crisis política y social que es mediatiza con la creación del, durante algún tiempo, principal partido de la izquierda electoral. El segundo acontecimiento lo representa la irrupción del movimiento indígena zapatista, que introduce en la agenda de discusión pública ${ }^{9}$ las condiciones de vida de los indígenas mexicanos y la reiteración de los derechos y culturas de los pueblos originarios, además de una serie de propuestas en los rubros de salud y educación

${ }^{8}$ Como factores externos podemos mencionar la crisis del socialismo real, con el consecuente derrumbe de los regímenes de Europa del Este, en especial la Unión Soviética. Ante la ausencia de un paradigma de izquierda a nivel mundial, y bajo el influjo del proceso democrático en términos electorales que se estaba dando en el país, algunas organizaciones decidieron impulsar el trabajo político-electoral de tendencia izquierdista y pactaron acuerdos con organismos políticos afines, la mayoría de organizaciones sociales deciden incorporarse entre 1989 y 1991 al Partido de la Revolución Democrática (PRD).

${ }^{9}$ La posición de los Zapatistas es muy clara. Lo que reclaman no es la inclusión sino participación tanto en la construcción de la democracia en México como en el discurso de los "derechos humanos". Si bien los derechos humanos, como la ética del discurso y de la inclusión, es más conveniente tenerlos que no tenerlos, también es cierto que la mayoría de los receptores de los derechos humanos no han tenido oportunidad de contribuir a su formulación y a su ejercicio. (Mignolo, 2001, págs. 33- 34) 
que siguen vigentes y que han llevado a cabo en los llamados municipios autónomos, en el sureste estado de Chiapas.

Otro rasgo que emparenta a las llamadas escuelas populares es la reiteración del discurso sobre la justicia social. Discurso que supone de entrada, una congruencia con las prácticas escolares, centradas en la justicia como parte de la atmósfera escolar. Pensar la justicia social en relación con la justicia escolar, implica pensar la escuela como un espacio en donde se pueden establecer dos perspectivas: como un subsistema que reproduce las desigualdades sociales, que instrumenta el orden establecido y que mantiene la estratificación social, o la escuela como motor de cambio social. Para las escuelas populares los aportes de Freire (Freire, 2005), fueron fundamentales para justificar discursivamente las prácticas educativas como prácticas de libertad de los oprimidos, los marginados, los condenados de la tierra como los llamó Fanon.

En todo caso en estas escuelas se establecen los intereses cognoscitivos desde el ámbito de una supuesta vida comunitaria. Los intereses cognoscitivos son fundamentales pues se vuelven marcos para la acción. Los enunciados acerca de los fenómenos y los acontecimientos se traducen en acciones racionales con respecto a fines de corte instrumental y estratégico, pero también el ámbito de los fenómenos de las personas y de lo social, se manifiesta en intencionalidades comunicativas, el llamado saber práctico. ${ }^{10}$ Un registro distinto tiene la intencionalidad cognoscitiva de emancipación, pues si bien conecta un saber teórico con una práctica vivida, reconoce las trampas de una comunicación sistemáticamente deformada y de una naturalización de la experiencia, con lo que los marcos de actuación están orientados a la eliminación de las coerciones naturalizadas o bien en la eliminación de una supuesta objetividad enraizada en motivos inconscientes o intereses reprimidos. Hacia estos fines se orienta la educación popular de la UPREZ, por lo menos discursivamente, y se piensa en la

\footnotetext{
${ }^{10}$ Mientras que el interés cognoscitivo práctico y el interés cognoscitivo técnico tienen sus bases en estructuras de acción y experiencia profundas (¿invariables?) y están vinculados a los elementos constitutivos de los sistemas sociales, el interés cognoscitivo emancipatorio posee un estatuto derivado. (Habermas, 1990, pág. 324)
} 
construcción de una mayor justicia social como el objetivo de corto, mediano y largo plazo, como objetivo político.

\section{Las promesas incumplidas... Sin remordimiento}

Específicamente en educación media superior tres son los asuntos de política pública que impactan las pretensiones de justicia social en educación: cobertura, porcentaje de escuelas públicas y eficiencia terminal. En este sentido los últimos datos oficiales disponibles se remontan al ciclo escolar 2015- 2016, tanto los que aporta el Instituto Nacional para la Evaluación de la Educación (INEE) como los que maneja el Instituto Nacional de Estadística y Geografía (INEGI). De acuerdo al INEE, ${ }^{11}$ la tasa neta de cobertura para la educación media superior era de $59.5 \%$ (cincuenta y nueve punto cinco por ciento) en el ciclo escolar referido, no obstante que la Reforma Educativa de 2012 que modificó el Artículo Tercero Constitucional, establece la obligatoriedad del Estado de lograr la cobertura total, es decir el cien por ciento, para el ciclo escolar 2021- 2022. De acuerdo al mandato constitucional el gobierno necesita aportar los recursos económicos necesarios para ampliar la cobertura en este nivel, lo que implica fundamentalmente escuelas y maestros, a tres años de que el plazo se cumpla se ve difícil que se logre lo que constitucionalmente está señalado.

El aspecto anterior se complica si además se considera que la Encuesta Intercensal 2015, publicada en abril de 2016, por el Instituto Nacional de Estadística y Geografía (INEGI) ${ }^{12}$ establece que el número de jóvenes entre 15 y 17 años era para el ciclo escolar 2015- 2016 de 6.4 millones (recordemos también que la modificación al Artículo Tercero Constitucional de 2012, introduce el criterio de edad idónea para cursar estudios en el nivel medio superior de 15 a 17 años), de los cuales, según las cifras del INEE, ${ }^{13}$ que se encuentran en el documento titulado Estructura $y$

\footnotetext{
${ }^{11}$ Existe en la página del INEE un Banco de Indicadores Educativos en donde se presentan los indicadores que conforman el Panorama Educativo de México según apartado y año de publicación. El interesado puede descargar los archivos en formato PDF que a su vez contienen vínculos para descargar las tablas en formato de Excel. Fue consultada la página el día 1 de febrero de 2018. http://www.inee.edu.mx/index.php/bases-de-datos/banco-de-indicadores-educativos.

12 Consultada en: http://www.inegi.org.mx/saladeprensa/aproposito/2016/ni\%C3\%B102016_0.pdf. El día 1 de febrero de 2018.

${ }^{13}$ Página consultada el día 1 de febrero de 2018 en: http://www.inee.edu.mx/index.php/bases-dedatos/banco-de-indicadores-educativos.
} 
Dimensión del Sistema Educativo Nacional, para ese ciclo escolar eran 4 millones 985 mil 080 los matriculados en el sistema escolarizado de media superior, repartidos entre bachilleratos general, tecnológico y profesional técnico, además 301 mil 787 jóvenes estaban en educación media superior no escolarizada, con lo que son 713 mil 533 jóvenes entre 15 y 17 años los que quedan fuera de este nivel de estudios, además de considerar que esta cifra se incrementa con los 25 millones de individuos cuyas edades, para esas fechas, iban de los 18 a los 29 años. Lo hasta aquí señalado constituye el primer factor que limita las aspiraciones de justicia social de los jóvenes en edad de cursar estudios de bachillerato, en resumidas cuentas no existen las escuelas suficientes para albergar a la población idónea (lo que motiva la pregunta de ¿qué alternativas tienen los jóvenes en edad no idónea para estudiar?) entre 15 y 17 años, pues de acuerdo a los datos oficiales más de 700 mil jóvenes quedaron fuera en el ciclo escolar 2015- 2016 de la educación media superior.

Segundo factor que limita las aspiraciones de justicia social: si bien en la educación básica existe un predominio de sostenimiento público, en la educación media superior el $18.6 \%$ de los alumnos asistió a planteles privados, que representa el $32.8 \%$ del total, es decir que uno de cada tres planteles en este nivel, era de sostenimiento privado de acuerdo a las tablas y a la información aportada por el INEE, para el ciclo escolar 2015- 2016 que es el último con información disponible. Lo que se convierte en un factor de justicia social pues tiene que ver con un asunto nada menor: el tipo de financiamiento de las escuelas de nivel medio superior. Instituciones que con sostenimiento privado, atienden a grupos con menos estudiantes que las oficiales, con profesores que en condiciones laborales precarias trabajan con criterios de eficiencia y calidad. En el caso de las instituciones públicas se ha incorporado paulatinamente al ámbito escolar los criterios administrativos de eficiencia y la pretensión técnico instrumental de calidad, referidas a aspectos de: eficiencia terminal, aprobación y aprovechamiento escolar. Si bien las escuelas públicas no son gratuitas pues el padre de familia tiene que cargar con el costo de la inscripción, uniformes, libros y materiales escolares en general, no se compara 
con el costo que tiene estudiar en una escuela particular. En consecuencia los aspirantes a estudiar en este nivel, tienen que optar por: dejar de estudiar, estudiar en escuelas que no satisfacen sus expectativas educativas o pagar una escuela particular.

De acuerdo a la misma fuente (INEE) y con respecto a aprobación y eficiencia terminal, los últimos datos disponibles están referidos al ciclo escolar 2014- 2015, el documento que explica estos criterios se interroga acerca de ¿cómo avanzan los alumnos en su trayectoria escolar? y se explican a partir de la Tasa de Aprobación (TA) y la Tasa de Eficiencia Terminal (TET). Se hacen algunas consideraciones al respecto de estos indicadores, en primer lugar, que para seguir una trayectoria regular es necesario inscribirse en cada nivel educativo en la edad idónea y transitar de manera consecutiva entre grados en cada ciclo escolar y cada nivel educativo, lo que significa en términos llanos no repetir el grado cursado y pasar al siguiente nivel educativo. En segundo lugar, la TA establece el número de alumnos que al término de un ciclo escolar cumplen con los criterios para ser promovidos al grado inmediato superior y se mide con respecto al número total de alumnos matriculados al final del ciclo escolar, esto es importante porque en estas cifras no se considera a los alumnos que a lo largo del ciclo escolar abandonaron la escuela, pues de hacerse así la TA disminuiría porcentualmente. En tercer lugar, hay que considerar que en educación media superior existe un periodo de regularización en que los alumnos pueden acreditar de manera extraordinaria las materias reprobadas, este periodo puede abarcar parte del siguiente semestre.

La Tasa de Aprobación (TA) para el ciclo escolar último registrado y de acuerdo a la Estadística 911 del ciclo escolar 2014- 2015, era en total del $71.5 \%$ sin embargo es importante acotar que si se analiza de manera diferenciada por grados escolares es menor en primer año y mayor en tercer año, así tenemos que se obtuvo en este ciclo escolar $65.6 \%$ en primer grado; $70.3 \%$ en segundo, y $80.7 \%$ en tercero. Lo que se puede interpretar es que al avanzar de grado escolar los alumnos que no aprueban dejan de formar parte de la generación que continúa y se obtiene en el siguiente grado escolar un porcentaje de aprobación mayor. De manera más 
simplificada ocurre un proceso de selectividad que resulta en tasas de aprobación más altas.

Por otro lado, en cuanto a la Tasa de Eficiencia Terminal (TET) hay que enfatizar que no sólo refiere que el estudiante avance de manera regular entre los distintos grados escolares, sino que además logre egresar, es decir mide la promoción de alumnos en los tiempos normales. En el ciclo escolar en cuestión se reporta que sólo el $67.3 \%$ logro promocionarse, aunque aquí también en el análisis de los datos pueden hacerse una serie de interpretaciones y diferencias, por ejemplo, que en el bachillerato general la TET era de $69.2 \%$ mientras que en profesional técnico la eficiencia terminal se estima en $54.1 \%$, como se aprecia en la información disponible. Conocer los factores que ocasionaron que el $32.7 \%$ de estudiantes no concluyeran sus estudios de nivel medio superior en el ciclo escolar 2014- 2015, ayudaría al desarrollo de estrategias desde las propias instituciones, que permita revertir estos datos. Posibilitar a los jóvenes opciones de desarrollo educativo encaminadas a ingresar a estudios universitarios o a trabajos mejor remunerados, entendiendo que los objetivos de inserción en el ámbito laboral y en educación superior, son ámbitos de política pública en donde la escuela tiene poca incidencia, no obstante es una exigencia social ineludible. Por las tres vías de análisis hasta aquí referidas, cobertura de educación media superior, financiamiento público de las escuelas y eficiencia terminal, los jóvenes mexicanos están condenados a padecer las injusticias del sistema económico y político imperante que además de criminalizar a la juventud, abona al crecimiento del narcotráfico, lo que genera un espectro social negativo, para las pretensiones de mejoramiento cultural, social y económico de este sector de la población.

Un factor más que atenta contra el derecho a la educación es la imposibilidad de que cada joven escoja en donde estudiar, ya que el examen de ingreso a este nivel establece una competencia por conseguir una matrícula. ${ }^{14}$ Cuando las escuelas

\footnotetext{
${ }^{14}$ El ingreso al nivel medio superior en la Zona Metropolitana de la Ciudad de México (ZMCM), que agrupa a todas las delegaciones y 22 municipios del Estado de México, es aplicado por una asociación civil que se promueve sin fines de lucro pero que tiene en sus manos todo el negocio de las pruebas estandarizadas. En su página oficial se lee: "El Centro Nacional de Evaluación para la Educación Superior (Ceneval) es una asociación civil sin fines de lucro cuya actividad principal es el diseño y la aplicación de instrumentos de evaluación de conocimientos, habilidades y competencias,
} 
ofertadas tienen distintas condiciones de infraestructura, capacidades académicas de los docentes, modelos de gestión escolar, ubicación geográfica y presupuestos que las distinguen y las enfrentan entre sí. Por otro lado, quienes acuden al examen presentan distintas condiciones económicas y de capital cultural, todo lo mencionado posibilita o limita el acceso a las escuelas del nivel medio superior de acuerdo a los deseos de los aspirantes.

En estas condiciones de la educación media superior, la UPREZ ha desarrollado acciones enfocadas a la creación de escuelas públicas en este nivel, en la reivindicación de empleos para los jóvenes y en demandas de infraestructura urbana. Todo englobado en el discurso sobre la justicia social, con lo que logra movilizar a padres de familia y alumnos en la consecución de dichos objetivos. Lamentablemente el discurso sobre la justicia social se constriñe a la creación de escuelas, su reconocimiento, las plazas de los maestros y la autonomía administrativa y financiera, que esconde en muchos de los casos la falta de claridad en el manejo de recursos autogenerados que no son sino las aportaciones de padres de familia vía una inscripción. El faltante que tiene el proyecto educativo de la UPREZ es el tipo de relaciones que se establecen entre los dirigentes de la organización con los directivos de las escuelas, pues en muchos de los casos están basadas en relaciones arbitrarias de subordinación y obediencia mediante la abierta o velada amenaza de la incorporación de las demandas de construcción, equipo y mobiliario de las escuelas en los pliegos petitorios que negocian los dirigentes con los funcionarios del gobierno del Estado de México.

En otro nivel entre directores y profesores la amenaza abierta o velada se da en relación con la conservación del empleo, el tipo de horarios que se le asignan al profesor, el incremento o decremento de horas. En consecuencia, es urgente la posibilidad de reflexión que permita marcos de actuación distintos y más amplios,

así como el análisis y la difusión de los resultados que arrojan las pruebas... Los instrumentos de medición que elabora el Centro proceden de procesos estandarizados de diseño y construcción, apegados a las normas internacionales; en su elaboración participan numerosos cuerpos colegiados...". Fue creado en 1994 mediante acuerdo de la Asociación Nacional de Universidades e Institutos de Enseñanza Superior (ANUIES). 
incluso procesos formativos horizontales que se encaminen a la formación pedagógica, que trasciendan las concepciones instrumentalistas de la educación. Estas diferentes concepciones son señaladas por los profesores entrevistados y se matizan en relación con factores como: antigüedad en la institución, simpatía o militancia en la organización (UPREZ), si el docente ha ocupado o no puestos de representación popular o de administración pública, si pertenece o no a los círculos burocráticos creados a lo interno de la organización en donde se toman decisiones de acciones a seguir y se discute la línea política y social. No obstante la relación que en estas escuelas se establece con los alumnos y padres de familia tienen sus particularidades, pues si bien se impone el uso del uniforme, el corte de pelo, la reiteración de una disciplina heterónoma, por otro lado, se discursa la importancia de una conciencia de clase social que esté atenta de los eventos nacionales e internacionales que lastiman la dignidad de las personas, que afectan a las clases populares y se manifiesta en un activismo de las escuelas a través de mecanismos de movilización como son la marcha, el plantón, el mitin y de manera más frecuente el uso de las redes sociales para la denuncia y la protesta. Formas de acción social que posibilitan la reivindicación de una serie de derechos y el logro de beneficios materiales para las escuelas y los jóvenes, en donde por cierto el papel del orientador se vuelve fundamental pues por un lado impone la disciplina a los jóvenes y por el otro inculca un sentido libertario de identificación y participación social de clase, una dialéctica extraña que va de lo heterónomo a lo autónomo, una especie de bipolaridad discursiva y de acciones que recuerda el libro de Louis Stevenson El extraño caso del Dr. Jekyll y Mr. Hyde.

Un asunto que se desprende de lo anterior es acerca de interrogar cómo se va construyendo la pedagogía de las escuelas populares como la UPREZ, y consecuentemente el sujeto al que se orienta el saber pedagógico. Recordemos que la Pedagogía que nace con aspiraciones científicas en la modernidad articulaba saber y poder encaminados a un sujeto pedagógico: el sujeto de la infancia. ${ }^{15}$ Este

\footnotetext{
15 "Por un lado, la pedagogía diseña una infancia discriminada en tanto tal en virtud de la constatación de una carencia o de un conjunto de carencias: no posee la autonomía ni el buen juicio ni el tino propio de los adultos. Son cuerpos débiles, ingenuos, manipulables, en formación. Por otro lado, los niños son objeto de dos operaciones fundamentales: constituyen campo de estudio y de análisis y a
} 
interés generado por la infancia como objeto de estudio y de normalización, que nace con la modernidad, fue asignado a los pedagogos y a la escuela y extensivamente se orienta en la actualidad a los jóvenes. Es fundamental entender la relación entre sociedad (adultos) e individuo (niño) en ese contexto, lo que nos lleva a considerar que la identidad de los niños y jóvenes que se socializan está constituida en el marco de los universos lingüísticos relacionados con los adultos, entendida entonces la individuación como la forma específica de configuración de la individualidad de la niñez y la juventud, con toda la carga de inseguridad ontológica condicionada por la precariedad en que estos sectores están colocados en la actualidad.

Varios sociólogos aportan teoría a estos temas de socialización y de relación sociedad/ individuo. G. H. Mead ${ }^{16}$, por ejemplo, coloca el inicio de la configuración de la individualidad en el reconocimiento de la intersubjetividad y de la autointeracción, en esta perspectiva es el lenguaje el que construye las interacciones sociales. Por ello es el discurso adulto el que establece las consideraciones sobre la infancia y la juventud, es el lenguaje que opera en contextos culturales el que da origen a semánticas específicas siendo así entonces que el self-la identidad- deja de ser considerada a estados interiores del sujeto, para pasar a adquirir relevancia en la medida en que se exterioriza, en la dialéctica del Yo y el Mi:

El "yo" provoca al "mi" y al mismo tiempo reacciona a él. Tomados juntos constituyen una personalidad, tal como ella aparece en la experiencia social. La persona es esencialmente un proceso social que se lleva a cabo, con esas dos fases distinguibles. (Mead, 1973, pág. 205)

Dependiendo del reconocimiento de los otros y en la medida en que los adultos presuponen capacidad en el niño/ joven este se va constituyendo o fragmentando,

la vez son empujados a emigrar del seno de la familia a unas instituciones producidas a efectos de contenerlos en su ineptitud y de formarlos para que, justamente, puedan abandonar o superar la carencia que les es constitutiva. A la discriminación etaria le sigue una delimitación institucional." (Naradowsky, 1994, pág. 109)

16 "No pretendo plantear la cuestión metafísica de cómo una persona puede ser a la vez 'yo' y 'mi' sino investigar la significación de tal distinción desde el punto de vista de la conducta misma." (Mead, 1973, pág. 201) 
el paso del Yo al Mi es posible en la interacción lingüística que reconoce a los sujetos capaces de lenguaje:

Pero éste, el otro, se desliga de tal intuición reificante en cuanto el sujeto aparece no en el papel de un observador sino en el papel de un hablante y, desde la perspectiva social de un oyente que le sale al encuentro en el diálogo, aprende a verse y entenderse a sí mismo como alter ego de ese otro ego. (Habermas J. , 1990, pág. 210)

El reconocimiento en el otro es la parte sustancial del planteamiento de Mead, interpretar la reacción de comportamiento del otro en la práctica de interacción hablante. La importancia del Yo hablante puede adquirir significación en la medida que esté presente el otro participante y activo. Por ello el papel del orientador es fundamental para que en este tipo de escuelas populares que reivindican un lugar relevante a los jóvenes/niños, se luche por alejarse de la pedagogización de la juventud/infancia, es decir del proceso de infantilización de una parte de la sociedad en el que la escuela juega un papel central pues escolarización e infantilización son dos fenómenos que corren paralelamente. La pedagogía inventa un discurso destinado a normar los saberes en las instituciones escolares para una infancia/juventud normal que se incorpore a una sociedad ideal.

Con lo señalado queda claro que es la institución escolar, la escuela, el dispositivo que la modernidad inventa para encerrar a la juventud/niñez. Encierro corpóreo pero también simbólico en las categorías que la pedagogía inventa para resignificar la juventud/niñez. Si los afanes educativos y políticos de las escuelas populares están encaminados a la formación de un sujeto crítico y reflexivo, un eje de lucha y transformación lo constituyen las relaciones entre los participantes del espacio escolar en un primer momento, a saber: directivos, profesores, pero fundamentalmente en el espacio de relaciones que se establecen entre orientadores y alumnos. La relevancia que en la UPREZ tienen los orientadores está determinada por la cercanía que tienen con padres de familia y alumnos, por la intermediación que ejercen entre profesores horas clase y alumnos y entre directivos y alumnos, por ello una de las interrogantes que surge es sobre las capacidades críticas, reflexivas, políticas y éticas del propio orientador. 


\section{La teoría de la justicia social}

Las escuelas UPREZ discursan trabajar por la justicia social a través del acercamiento de clase social de los individuos, persiguiendo reducir progresivamente las desigualdades económicas, empezando por la reivindicación de una mejor educación, un mejor sistema de salud pública, mejores condiciones sociales en las colonias en donde vive la clase trabajadora y, sobre todo, a través de la reivindicación de empleos mejor pagados y de democracia sindical. Lo que ha llevado a los maestros que militan en esta organización a aliarse con referentes estatales y nacionales más amplios y consolidados como la Coordinadora Nacional de Trabajadores de la Educación (CNTE) para oponerse por ejemplo a la aplicación de la Reforma Educativa de 2012. Otro frente al que se han vinculado es el político electoral, en primera instancia en alianza con el Partido de la Revolución Democrática (PRD) y ahora también con el Movimiento de Regeneración Nacional (MORENA). Lo que lleva a una posición de comunismo liberal como la llama Slavoj Zizek (Zizek, 2009), o de lucha por una igualdad de posiciones como la nombra Francoise Dubet (Dubet, 2011).

Si bien las políticas gubernamentales están encaminadas a una igualdad de oportunidades, como si las desigualdades sociales no fueran un problema, y se actúa en el mejor de los casos promoviendo que los individuos tengan las mismas oportunidades de acceder a todas las posiciones en función de su mérito. Esto último en una idea de hacer la competencia social equitativa, en el trabajo y en la educación, pensando que el mundo puede ser justo si cada uno ocupa el lugar que se merece, y por lo tanto se desarrollan acciones tendientes al otorgamiento de becas para estudiar y a subsidiar ciertos servicios públicos, desconociendo la historia personal y las condicionantes económicas, sociales y culturales de cada persona.

Las diferencias en uno y otro modelo son fundamentales, pues mientras en el modelo de igualdad de posiciones las desigualdades son percibidas como de clase y tienen que ver con las personas que son explotadas, en el modelo de igualdad de oportunidades, las desigualdades son percibidas como de oportunidades y se 
considera que las víctimas son los inmigrantes, las mujeres, los jóvenes, los homosexuales, por lo que se implementan políticas compensatorias que terminan por reproducir el círculo de marginación de estos grupos sociales.

La gran paradoja de estas dos perspectivas teóricas que dan origen a acciones sociales, es que las organizaciones populares y de izquierda como la UPREZ, terminan por orientar su actuar a conseguir becas, subsidios, vivienda popular, reconocimiento de nuevos servicios educativos, aplicando un corporativismo y control sobre sus alumnos, maestros y padres de familia bajo la promesa de obtener esas viviendas, esas escuelas y esas becas, reproduciendo las prácticas gubernamentales que dicen combatir, aunque con discursos de reivindicación de procesos horizontales y comunitarios. Renuncian a realizar procesos teóricos y prácticos que se orienten a articular acciones que permitan el cambio del modelo económico que ha creado las condiciones políticas, económicas, sociales y culturales actuales. Lo que se pierde de vista es que la experiencia histórica muestra que aquellas sociedades más igualitarias, donde las desigualdades son menos fuertes, son a su vez más tolerantes y en consecuencia menos violentas y tienen por tanto un mejor sistema educativo. Lo que quiere decir en otros términos que entre mayor sea la igualdad social, más fuerte será la igualdad de oportunidades, viéndolo en la escuela, si disminuyen las desigualdades de posiciones (entre los individuos y entre las propias escuelas), se espera aumente la igualdad de oportunidades. No ocurre lo mismo si se aumenta la igualdad de oportunidades, pues sucede que no aumenta proporcionalmente la igualdad de posiciones, incluso puede aumentar la desigualdad.

Si se está en una sociedad relativamente igualitaria, los mecanismos de asimilación son más favorables que en una sociedad profundamente desigual. Si se tiene un sistema educativo con buenas condiciones de infraestructura, donde exista una concepción de formación de los maestros, además de condiciones salariales adecuadas, eso contribuye a la igualdad. Un paso importante en la búsqueda de instituciones justas está referido a considerar que en la escuela no sólo es importante el saber, el conocimiento, sino considerar las emociones y las pasiones, acercando la escuela a la vida, lo que se vive en la cotidianidad de los alumnos y 
de los maestros. Tomando distancia de posicionar al profesor en el papel de una especie de cura laico que habla sólo en nombre de la razón, como intermediario entre la ciencia y el que no sabe, el alumno.

La lucha de las escuelas UPREZ se orienta entonces a la formación de ciudadanos democráticos y con sentido de justicia social, en una idea de emancipación que sobrepasa los marcos de la escuela, ampliándolos a todo lo social. Para ello plantean que se tiene que cambiar a la escuela y en primera instancia su transformación tiene que ver con acabar con el mito de santuario en el que se fundó y que se ha venido reforzando a lo largo de los años. Los maestros de esta organización entienden sin ingenuidades ni romanticismos, las limitaciones que tiene la vida democrática en un país como México, donde se han sedimentado tradiciones culturales de corporativismo, simulación y trampa. Además, en los límites que la propia idea de justicia tiene con respecto al deseo, la ley, la norma y el poder. Si bien logran identificar las prácticas gubernamentales de corporativismo y control, entre más compromiso e identificación tengan con su organización UPREZ, mayor dificultad muestran para reconocer internamente estas mismas prácticas, por lo que recurren a los discursos redentores. Además, han renunciado a la transformación del modelo económico imperante al incorporarse al juego democrático electoral que ha permitido a los integrantes de esta organización ocupar puestos de representación popular en los tres niveles de gobierno. Sin embargo, en las entrevistas con profesores horas clase y con alumnos estas problemáticas se muestran en todas sus contradicciones, pareciera pues que se necesita cierta epojée ${ }^{17}$ para ubicar las contradicciones internas de la organización social en donde voluntaria e involuntariamente se está inserto.

\section{Discursos redentores, disyuntivas docentes}

Llamamos redentores a los discursos que hacen suya la idea de progreso entendida como la administración social del alma del estudiante con lo cual se pretende

\footnotetext{
${ }^{17}$ El término procedente de la antigüedad griega era utilizado por los escépticos al encontrarse ante dos proposiciones igualmente defendibles pero contradictorias entre sí. Etimológicamente significa suspender y en general se aplica a la decisión de suspender el juicio. Husserl la incorporó en su método fenomenológico, al referirse a la puesta entre paréntesis de la realidad del mundo que conduce a la apropiación de la realidad del yo, de la propia conciencia.
} 
producir el cambio y la mejora del individuo. Para que esto ocurra, la imagen del docente que se promueve es la de agente redentor, pretendiendo que la acción del docente y de la escuela esté al servicio de los ideales democráticos. ${ }^{18}$ Así que proponemos una caracterización de los discursos que los dirigentes y maestros de la UPREZ discursan en las entrevistas realizadas.

Primer discurso redentor: A mayor escolaridad mejores oportunidades de ocupación. Una gran parte del descontento con la escuela tiene que ver con la insatisfacción que provoca el que los mayores niveles de escolaridad no se reflejen con la ocupación de un empleo bien remunerado. En los hechos, los niveles de escolaridad más altos han tenido una devaluación en el mercado de empleos, lo que coloca a las escuelas en situaciones de mayor exigencia social. La insatisfacción que se le señala a las escuelas de varios frentes (padres, alumnos, gobierno), deja de lado el análisis de las condiciones de desarrollo económico de nuestro país que ha impactado en la desilusión que tienen los jóvenes por el futuro, idea expresada por primera vez, desde hace más de diez años, por más del cincuenta por ciento de los entrevistados en la Encuesta Nacional de la Juventud realizada en $2005 .^{19}$

De acuerdo con datos del INEE (2015), existen diferencias muy importantes en la tasa de ocupación de hombres y mujeres, independientemente del grupo de edad del que se trate y de la escolaridad. Por ejemplo, la tasa de ocupación es de $71.6 \%$ para mujeres de más de 25 años que tienen educación superior como grado máximo de escolaridad en comparación con los hombres, cuya proporción es de $88.6 \%$. Esto significa una distancia de 17 puntos porcentuales, que aumenta cuando se analizan otros grados de escolaridad y grupos de edad entre hombres y mujeres.

\footnotetext{
${ }^{18}$ Con independencia del carácter democrático que parezca tener esta retórica populista, ha servido para consolidar y encubrir las relaciones de poder en un campo desigual. (Popkewitz, 1998, pág. 32) ${ }^{19}$ Ver Néstor García Canclini. “Los jóvenes no se ven como el futuro: ¿serán el presente?”, en Pensamiento Iberoamericano, N. ${ }^{\circ}$ 3, 2da. Época, 2008.
} 


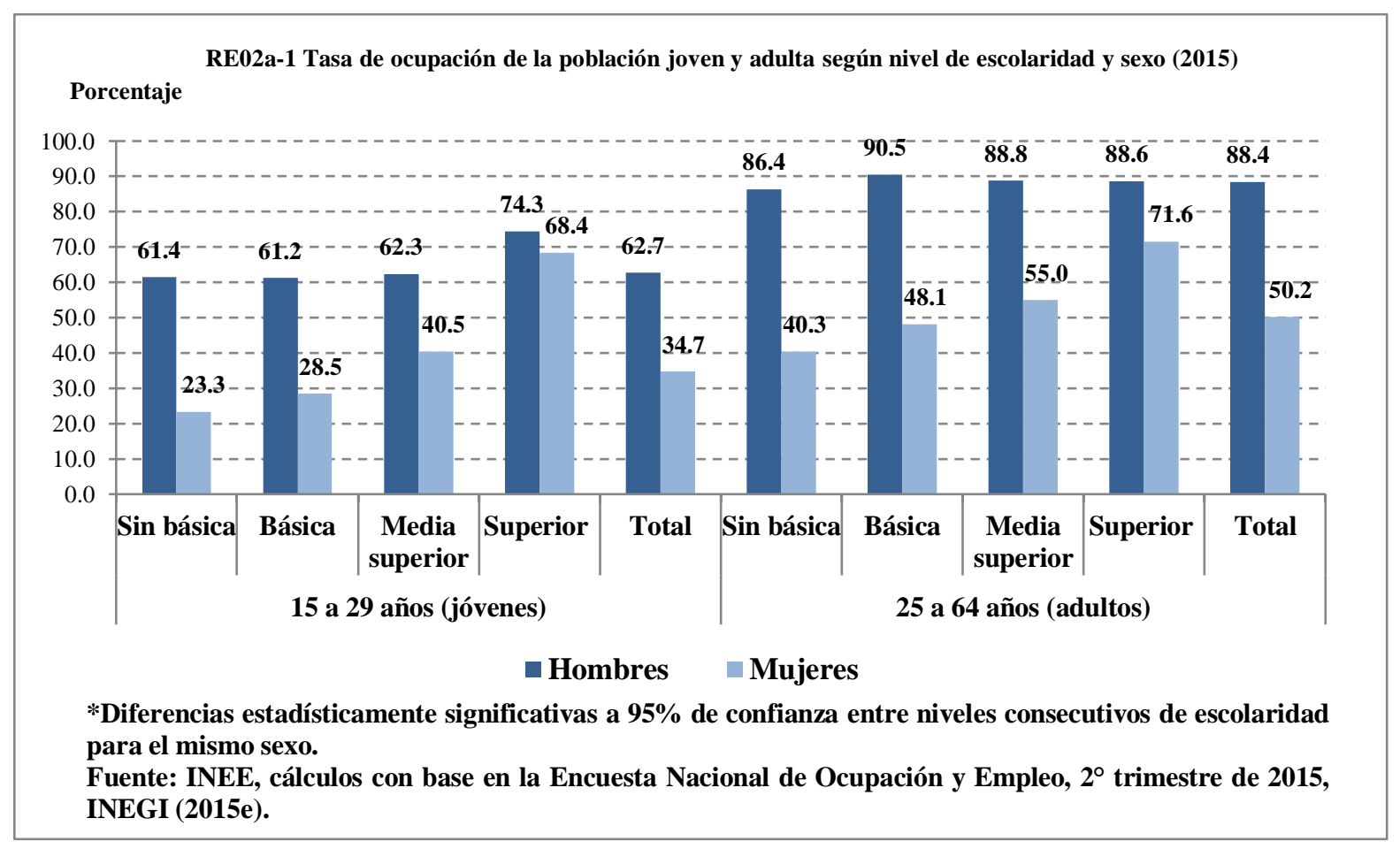

GRÁFICA 1. RELACIÓN ENTRE OCUPACIÓN, SEXO Y ESCOLARIDAD

No es interés de este texto analizar la remuneración de los empleos para quien ostenta bachillerato, con lo que tendríamos un panorama más completo y quizá también más desalentador de la relación que existe entre sexo, edad, escolaridad, ocupación y remuneración económica. Por lo que este primer discurso redentor, resumido en la necesidad de la escolarización para mejorar el nivel de vida de la población y en una demanda social y política de la UPREZ por crear escuelas de nivel medio superior, esconde un discurso sesgado, pues en México la escolaridad no es determinante para obtener un empleo, aunque vale decir que entre mayores niveles de escolaridad se tengan aumenta la probabilidad de ocupación.

Segundo discurso redentor: En la escuela se educa al ciudadano ${ }^{20}$ que el país necesita. La escuela ha transitado por distintas etapas históricas donde pueden

\footnotetext{
${ }^{20}$ En el Acuerdo 444 publicado en el Diario Oficial de la Federación (DOF) el 21 de octubre de 2008 , se establecen las competencias que constituyen el marco curricular común del Sistema Nacional de Bachillerato. La competencia genérica 9 refiere la responsabilidad social del alumno, señalando la importancia de que participe: “... con una conciencia cívica y ética en la vida de su comunidad, región, México y el mundo, con los atributos siguientes... Toma decisiones a fin de contribuir a la equidad, bienestar y desarrollo democrático de la sociedad... Contribuye a alcanzar un equilibrio entre el interés y bienestar individual y el interés general de la sociedad...”.
} 
distinguirse los encargos que en ella se depositan, como espacio de educación, capacitación y formación del recurso humano para el desarrollo económico del país. De manera más actual, el estudiante como cliente, con lo que las exigencias a los docentes y a la escuela son entonces de eficiencia y eficacia, con el consecuente predominio de las lógicas de mercado, en un bien público como es el conocimiento y la educación. Desde estas perspectivas el concebir al estudiante como el futuro ciudadano no se corresponde con la idea del cliente que necesita calidad en su educación. Por ello la concepción de ciudadanía se vacía de sentido, aún más cuando se analizan las perversiones en la práctica política y los juegos de poder en la aplicación de la ley. Este vaciamiento de sentido se pretende llenar, en el discurso y en la práctica, en lo que llamamos el fundamentalismo autoritario, tesis del choque de civilizaciones que sostiene Samuel P. Huntington:

La teoría de la distintividad, la teoría de la identidad social, la sociobiología y la teoría de la atribución, desarrolladas todas ellas en el tramo final del siglo $\mathrm{XX}$, sustentan la conclusión de que las raíces del odio, de la rivalidad, de la necesidad de enemigos, de la violencia personal y de grupo y de la guerra se encuentran en la psicología y en la condición humana. (Huntington, 2004, pág. 51)

Además, la idea de ciudadanía se contrapone a las tendencias culturales posmodernas del llamado nuevo capitalismo. Recordemos en un primer momento que la idea de ciudadanía nace en las polis griegas e implicaba una concepción de educación centrada en el hombre político, en una doble perspectiva: hacer miembro de la sociedad a todo hombre libre y obediente del Estado. El medio para lograr tal pretensión dio origen a la práctica sofística y a la Paideia socrático platónica. Aunque el conocimiento que se tiene de los sofistas está condicionado por la presentación crítica que de ellos hace Platón, la fuerza argumentativa de Gorgias uno de sus más importantes representantes, permite dimensionar la importancia que le dan al uso del lenguaje y el poder que éste tiene. ${ }^{21}$ La retórica entonces

\footnotetext{
${ }^{21} \mathrm{~A}$ mi modo de ver, el estar apto para persuadir con sus discursos a los jueces en los tribunales, a los senadores en el Senado, al pueblo en las asambleas; en una palabra a todos los que componen toda clase de reuniones políticas. Este talento pondrá a tus pies al médico y al maestro de gimnasia y se verá que el economista se habrá enriquecido no para él, sino para otro, para ti, que posees el arte de hablar y ganar el espíritu de las multitudes. (Platón, 2013, pág. 55)
} 
centra su fuerza expresiva en el convencimiento. ${ }^{22}$ Frente a esta propuesta educativa, surge la Paideia socrático- platónica, en donde se plantea el correcto uso del logos orientado a la inserción en la polis, en un esquema de búsqueda de la verdad a través de la dialéctica que promueve el conocimiento interior. En esta perspectiva la búsqueda de la areté (virtud) personal se vuelve fundamental pues está relacionada con el conocimiento del Bien, apunta a la episteme, al conocimiento verdadero. ${ }^{23}$

Con lo señalado es evidente que no es nueva la idea de la escuela como espacio de socialización y en educación media superior la escuela con tareas de construcción de una sociedad democrática. Sin embargo, las tendencias de una forma de posmodernismo, apuntan al individualismo asocial (no necesariamente antisocial), lo que hace recordar así mismo a Hobbes quien explica el comportamiento individual en función de elecciones racionales favorables a sus intereses. En una lógica de mercado este pensamiento es el más adecuado, pues en toda competencia se producen ganadores y perdedores y entonces nadie tendría que asumir responsabilidades por los perdedores, es decir dinamita la vida social y cierta solidaridad orgánica.

Si analizamos las dinámicas de reformas que atentan contra los derechos laborales, encontramos que gran parte de las tendencias, sino es que todas, apuntan a la erosión de las normas de protección del trabajador. Procesos de pérdida del sentido de colectividad, es decir de individualización. Con lo que este discurso redentor desconoce el contexto en el que interactúan los alumnos y sus familias, lo que implica entonces recuperar la fuerza de la escuela para vincularse a acciones que incidan en la transformación de otras formas de relación social más allá de la escuela misma.

\footnotetext{
${ }^{22}$ Puesto que todas estas prácticas constituyen un formidable sistema institucional ("represivo" como se dice ahora), era normal que se desarrollara una burla de la retórica, una retórica "negra" (sospechas, desprecio, ironías): juegos, parodias, alusiones eróticas u obscenas, bromas escolares, toda una práctica de colegiales (que todavía queda por explorar y constituir como código cultural). (Barthes, 1974, pág. 10)

${ }^{23}$ Surgió así una gimnasia del pensamiento que pronto tuvo tantos partidarios y admiradores como la del cuerpo y que no tardó en ser reconocida como lo que ésta venía siendo ya desde antiguo: como una nueva forma de la paideia. La "dialéctica" socrática era una planta indígena peculiar, la antítesis más completa del método educativo de los sofistas, que había aparecido simultáneamente con aquélla. (Jaeger, 2001, pág. 46)
} 
Tercer discurso redentor: La escuela contribuye a la construcción de procesos de inclusión social. Como sabemos, en las sociedades tradicionales y en las sociedades capitalistas industriales, existía una necesidad de garantizar la reproducción por lo que se requería niveles básicos de cohesión social para que la reproducción pudiera tener vigencia. El salario fue la expresión de esta relación, además de una serie de dispositivos institucionales de organización sindical y de protección de derechos sociales. Sin embargo, en la actualidad la transformación de las condiciones de producción, con la incorporación de las tecnologías de la información y de la comunicación, ha dinamitado las bases de relación salarial y precarizado los contratos de trabajo, con la consiguiente exclusión de sectores sociales. Es decir, procesos de desafiliación de sectores de la población. El excluido como marginado social, es decir con poca o nula posibilidad de actuar socialmente. La desafiliación más en este sentido de ausencia, de incidencia o participación en las estructuras sociales.

Construir procesos de inclusión social como se ve no será producto de las estructuras institucionales, sino de acciones voluntarias de solidaridad que vayan contra los determinismos del mercado que expulsan a importantes capas de la población del uso de bienes y servicios. En este aspecto la escuela puede, no con una lógica institucional que pretenda el control, el rigor administrativo y académico, tampoco con acciones de autoritarismo docente y directivo, mucho menos en una idea de homologación de pensamientos y personalidades, sino con una postura ética y política de solidaridad con los expulsados, promover niveles de adhesión a la justicia social.

Adhesión que, de acuerdo con Giddens, debe ser reflexiva no sólo como dimensión cognitiva, sino emocional. (Giddens, 1997). Los procesos reflexivos permeados por la razón, la emoción y el deseo cada vez serán más necesarios, pues cada vez más nos enfrentaremos a temáticas que superan las cuestiones políticas tradicionales, así como a procesos de construcción de nuevas identidades juveniles. De ahí que la actividad que desarrollan las escuelas de organización como la UPREZ, reconociendo los vicios que han fomentado y tolerado, y con la firme convicción de combatirlos y acabar con ellos, sin renunciar a la construcción de procesos 
colectivos de subjetivación social, son una posibilidad para crear alternativas no contestatarias sino distintas en la generación de sujetos sociales críticos, reflexivos y científicos como rezaba el viejo lema que dio origen a las primeras escuelas populares y en donde la actividad de los pedagogos (directivos, orientadores y profesores) es fundamental para lograr formas distintas de concebir la docencia.

\section{Pinceladas para un final momentáneo}

Pensar en las escuelas populares o de organización la relación con la justicia, implicaría retomar una discusión bajo diferentes perspectivas, más allá de la denuncia, siempre necesaria, que sus dirigentes y militantes hacen acerca del modelo económico actual que día con día cancela la posibilidad de futuro de los jóvenes en sus perspectivas de contar con niveles mínimos de bienestar en educación, salud, seguridad pública y empleo. Si las escuelas populares o de organización quieren contribuir al cambio cultural, social y político de la nación, es necesario primero que resuelvan colectivamente las evidentes contradicciones entre lo que discursan (Dr. Jekyll) y sus acciones (Mr. Hyde). Segundo que incorporen a su agenda de discusión la necesidad de construir una educación que se pregunte acerca de ¿cuáles son las actitudes, aptitudes y conocimientos mínimos de los que el joven escolarizado debe tener dominio al final de cada trayecto formativo? Para no condenarlos a un nivel de marginación cultural con respecto a aquellos jóvenes que tienen condiciones culturales más favorables relacionadas con su nivel socioeconómico. Es decir que si la escuela es eficaz en la educación que imparte está contribuyendo a ser una escuela justa.

Tercero no borrar por necesidades de control y corporativismo la crítica y autocrítica de los profesores, pedagogos, directivos, dirigentes y jóvenes, de los fenómenos que se viven a lo interno de las escuelas de organización o populares, de los fenómenos nacionales e internacionales que afectan a las poblaciones precarias, aspirando a la praxis (teórica y práctica) que permita la construcción de un futuro distinto. Como lo señala la teoría de la justicia de (Fraser, 2006), en la época actual posmoderna, pos-socialista, la teoría de la justicia incorpora tres ejes fundamentales: la redistribución, el reconocimiento y la representatividad, lo que a 
nivel de las escuelas populares o de organización se convierte en ejes programáticos para interrogarse sobre: a) La infraestructura educativa necesaria; b) La formación docente centrada en la diferencia; c) Los planes y programas de estudio más adecuados para la población de la que se trate, considerando los orígenes sociales de los jóvenes; d) Las perspectiva de relación con la comunidad rebasando los marcos escolares; e) Los trayectos formativos dinámicos y flexibles para los jóvenes y f) Los mecanismos de representación que incorpore la voz, palabra y pensamiento de los jóvenes en la toma de decisiones de los asuntos públicos de la escuela.

\section{CONCLUSIÓN}

La escuela puede ser el espacio de reproducción de las desigualdades sociales, de las exclusiones y los expulsados del sistema o el espacio donde se trabaje para la inclusión y el acercamiento de los que, debido al sistema económico imperante, quedan fuera de la escuela y de cierta protección social. Para el sistema económico imperante las personas se vuelven cifras, estadísticas, indicadores. Despersonalizadas las cifras, las estadísticas, los indicadores, esconden las tragedias personales de quienes ven limitadas sus posibilidades de acceso a la educación, a la salud a condiciones mínimas de subsistencia.

En este arduo y sinuoso camino por lograr mejores condiciones de vida, las escuelas populares pueden comenzar retomando los objetivos fundacionales de su origen, posibilitando una reflexión colectiva profunda sobre los fines originales que perseguían, señalando los vicios corporativos que han fomentado, las lógicas de poder que sostienen y haciendo un mea culpa sobre las corrupciones que han tolerado y reproducido.

Un aspecto fundamental en las escuelas populares lo tiene el discurso de la justicia social, discurso que si se sostiene en posiciones éticas y políticas, permea el trabajo escolar, estableciéndose una correspondencia entre justicia social y justicia escolar. Reflejada la justicia escolar, en una consideración, distinta a la oficial, de la formación docente, en planes, programas y proyectos. En la incorporación de los estudiantes a temas y espacios que históricamente les han estado prohibidos. Y en 
la medida de las convicciones personales y colectivas trascender los espacios escolares para lograr la transformación de las formas de relación intersubjetivas basadas en la manipulación, incidiendo incluso en el cambio de las prioridades gubernamentales, haciendo de la salud, la educación, la ciencia y la protección laboral los fundamentos de la función pública, en pocas palabras cambiando el modelo económico.

En su origen las escuelas de organización tenían un anhelo de transformación sustentado en la insatisfacción por lo que ocurría en la sociedad, cuestionaban lo que se presentaba como realidad oficial y no aceptaban las cosas porque sí. Se parecían a lo que Lewis Carroll creo como mundo de rebeldía con el personaje de Alicia y también del absurdo con los demás personajes, de manera similar a como lo hizo Kafka, pero a diferencia de éste en donde los personajes son aplastados por el absurdo, Alicia logra triunfar. También hoy se llega a cuestionar si no la época se encamina al mundo de oscuridad que George Orwell retrata en 1984, la magna obra que plantea el control de los cuerpos y del pensamiento, crítica de los totalitarismos de derecha y de izquierda, en donde el amor llega a ser altamente peligroso y las emociones y el sexo llegan a estar prohibidos, sólo el amor al gran hermano. Estas preguntas se complementaban, en los proyectos originarios de las escuelas populares, con otras más donde las disyuntivas eran: ¿seremos más felices aunque menos libres? o ¿La imaginación, ahora sí, llegará al poder y seremos gobernados por sujetos que construyan otro tipo de relaciones, más justas y democráticas? Interrogantes que siguen siendo válidas en una sociedad donde un sector se niega a que impere el conformismo, así como en el momento de su creación lo hicieron los sujetos, activistas, idealistas, románticos, profesores, pedagogos, orientadores, que dieron origen a muchas escuelas de organización, para que no se conviertan como hasta ahora en comparsas voluntarios e involuntarios del sistema económico y político imperante en México. En esencia para que las escuelas populares como la UPREZ, retomen los aspectos políticos y éticos de toda práctica pedagógica y sean congruente en las acciones cotidianas y permanentes con lo discursado y no padezcan más del Síndrome del Dr. Jekyll y Mr. Hyde, como lo recuerda la famosa novela de Louis Stevenson. 


\section{Bibliografía}

Aries, P. (1987). El niño y la vida familiar en el antiguo régimen. Madrid: Taurus.

Barthes, R. (1974). Investigaciones retóricas I. La antigua retórica. Barcelona: Ediciones Buenos Aires.

Bolos, S. (2003). Organizaciones Sociales y Gobiernos Municipales. México: Universidad iberoamericana.

Canclini, N. G. (2008). Los jóvenes no se ven como el futuro ¿serán el presente? Pensamiento Iberoaméricano, No. 3, 2da. Época.

Castellanos, L. (2007). México Armado: 1943-1981. México: ERA.

Dubet, F. (2011). Repensar la justicia social (contra el mito de la igualdad de oportunidades). México: Siglo XXI.

Educación, I. N. (2017). La Educación Obligatoria en México (Informe 2017). México: INEE.

Educación, I. N. (2016). Estructura y Dimensión del Sistema Educativo Nacional. México: INEE.

Fanon, F. (1983). Los condenados de la tierra. México: Fondo de Cultura Económica.

Fraser, N. (2006). ¿Redistribución o Reconocimiento? Un debate Políticofilosófico. Madrid, España: Morata.

Freire, P. (2005). Pedagogía del Oprimido. México: Siglo XXI Editores.

Geografía, I. N. (2017). Estadística a Propósito del día Internacional de la Juventud (Encuesta Intercensal 2015). México: INEGI.

Giddens, A. (1997). Consecuencias de la modernidad. Madrid: Alianza.

Habermas, J. (1990). Conocimiento e Interés. Argentina : Taurus.

Habermas, J. (1990). Pensamiento postmetafísico. Madrid: Taurus.

Huntington, S. (2004). ¿Quiénes somos? Los desafios a la identidad nacional estadounidense. Barcelona : Paidos. 
INEE. (2011). La educación media superior en México (informe 2010- 2011). México: Instituto Nacional para la Evaluación de la Educación.

Jaeger, W. (2001). Paideia. Los ideales de la cultura griega. México: Fondo de Cultura Económica.

Mead, G. H. (1973). Espíritu, persona y sociedad. Barcelona: Paidós.

Mignolo, W. (2001). Capitalismo y Geopolítica del conocimiento. Buenos Aires: Ediciones del Signo.

Naradowsky, M. (1994). Infancia y Poder: la conformación de la pedagogía moderna. Buenos Aires: Aique.

Platón. (2013). Diálogos (Gorgias o de la Retórica). España: Espasa.

Popkewitz, T. (1998). Los discursos redentores de las ciencias de la educación. Sevilla: Morón.

Zizek, S. (2009). Sobre la violencia. Seis reflexiones marginales. Barcelona: Paidós. 